\title{
Mortality and cancer in patients with new musculoskeletal episodes: a cohort study
}

\author{
Kelvin P Jordan and Peter Croft
}

\begin{abstract}
Background

The risk of serious outcome in persons presenting to primary care with common regional musculoskeletal problems is unknown.

Aim

To determine the risk of mortality and cancer in older patients presenting with new musculoskeletal problems.

Design of study

Cohort study.

Setting

One hundred and seventy-nine general practices contributing to the General Practice Research Database.

Method

Cases were 48206 people aged $\geq 50$ years, with a recorded musculoskeletal problem in 1996 but none during the previous 2 years. Cases were allocated to groups based on problem location (for example, the back). A total of 40254 controls had no musculoskeletal consultation during 1996 or during the previous 2 years. Outcome measures were mortality and recorded malignant and pre-malignant neoplasms 1 and 10 years after baseline consultation.

Results

Mortality rates in the first year of follow-up were higher for cases (373 per 10000 person-years) than controls (244). The hip (standardised mortality ratio 2.36; $95 \%$ confidence interval $[\mathrm{Cl}]=1.99$ to 2.77 compared to controls) and back $(2.07 ; 95 \% \mathrm{Cl}=1.87$ to 2.28$)$ groups had the highest 1-year rates. Ten-year mortality rates were closer between groups. Higher cancer rates were found for the back, hip, and neck groups. The first-year excess mortality in cases was only partly explained by cancer and other comorbidity (hip hazard ratio $1.72 ; 95 \% \mathrm{Cl}=1.43$ to 2.07 ; back $1.68 ; 95 \% \mathrm{Cl}=$ 1.49 to 1.90$)$.

\section{Conclusion}

New consulting episodes of musculoskeletal problems in the back or hip are associated with higher subsequent cancer rates and increased mortality risk in older people. Unexpected cancer and death in these patients remains rare but the ability of clinical signs and symptoms to identify persons at risk needs to be confirmed.

Keywords

cancer; primary care; mortality; musculoskeletal diseases.
\end{abstract}

\section{INTRODUCTION}

Regional musculoskeletal conditions, such as back or shoulder pain, are common in primary care. One challenge for health professionals is that regional pain can occasionally be the presenting symptom of serious disease such as cancer.

Studies of patients presenting with problems such as back pain have suggested that rates of serious diagnoses like cancer are low. ${ }^{1}$ However, epidemiological evidence about mortality from general population studies has suggested higher mortality, particularly cancer-related mortality, among people with widespread musculoskeletal pain..$^{2-4}$ Widespread pain might be a marker for other problems, but studies have also shown increased mortality in persons reporting regional musculoskeletal problems. ${ }^{3,4}$ However, another study found no increased risk of mortality or cancer in women with chronic pain. ${ }^{5}$

There are few published estimates of the risks of serious disease or mortality in older people who present in primary care with common musculoskeletal problems, and whether any such risks vary with location (for example, the back or knee). This study has compared mortality rates among patients presenting with a new musculoskeletal problem with controls not presenting with such a problem, overall and according to the

KP Jordan, PhD, reader in biostatistics; $P$ Croft, $M D$, professor of primary care epidemiology, Arthritis Research Campaign National Primary Care Centre, Keele University.

Address for correspondence

Kelvin P Jordan, Arthritis Research Campaign National Primary Care Centre, Primary Care Sciences, Keele University, Keele, Staffordshire ST5 5BG.

E-mail: k.p.jordan@cphc.keele.ac.uk

Submitted: 30 April 2009; Editor's response: 8 June 2009; final acceptance: 25 August 2009.

(C)British Journal of General Practice

This is the full-length article of an abridged version published in print. Cite this article as: Br J Gen Pract 2010; DOI: 10.3399/bjgp10X483526. 
location. It also compared the occurrence of one serious disease (cancer). The study was restricted to a group considered in guidelines about management of musculoskeletal problems to be at higher risk of serious problems, namely persons aged $\geq 50$ years.

\section{METHOD}

This was a cohort study, with a maximum 10 years of follow-up, set within the General Practice Research Database (GPRD). Participants had either consulted with a new musculoskeletal problem in 1996 ('new problem' defined by no record of a musculoskeletal consultation in the preceding 2 years: the 'cases'), or had no record of any musculoskeletal consultation during 1996 and the previous two calendar years (the 'controls').

The GPRD is a computerised, high-quality, database of routinely collected general practice consultation data within the UK, covering around 5\% of the population. ${ }^{6}$ Contributing practices are required to achieve a set standard in recording consultation data. The correctness of recorded morbidity codes assigned to patients in the GPRD has been examined for several conditions by comparison with external information such as hospital information. . $^{70}$

Potential cases and controls for this study were identified from general practices which contributed to the GPRD from before 1994 to at least the end of 1996. Participants had to be registered continuously at the practices between those dates. Cases were defined as all persons who (i) had at least one recorded consultation during 1996 for a musculoskeletal problem; (ii) had no recorded musculoskeletal consultation in the 24 months prior to their first musculoskeletal consultation in 1996; and (iii) were aged $\geq 50$ years at the time of this consultation. The definition of a musculoskeletal consultation was based on the morbidity Read Code (or OXMIS code equivalent) recorded in the general practice records. Read Codes are a common method of classification of morbidity in the UK in general practice. ${ }^{11}$ They form a hierarchy of diagnostic and process-of-care codes, with diagnostic codes grouped into chapters (for example, musculoskeletal, mental health). Musculoskeletal consultations were defined as a recorded code within Chapter N (Musculoskeletal and connective tissues disorders) plus relevant musculoskeletal codes from Chapters 1 (History and symptoms), R (Symptoms, signs, ill-defined conditions) and S (Injury and poisoning).

Cases were allocated to groups based on location of the problem (for example, the back or knee) at their first musculoskeletal consultation in 1996. Groups defined by back, hand/wrist, knee, hip,

\section{How this fits in}

Regional musculoskeletal problems are commonly seen in primary care.

However, the risk of mortality or serious morbidity in persons presenting with such problems is unknown. This study shows that new consulting episodes of musculoskeletal problems in the back or hip are associated with higher subsequent cancer rates and increased mortality risk in older people. Although

unexpected cancer and death in these patients remains rare, the ability of clinical signs and symptoms to identify persons at risk needs to be confirmed.

shoulder, neck, and foot were analysed in more detail (the 'case groups').

Controls were persons who had no recorded musculoskeletal consultation at any time during the calendar years 1994 to 1996 inclusive, matched by age, sex, and practice to cases. Some controls were matched to more than one case; hence the number of cases and controls are not identical. The baseline date was set at the date of first musculoskeletal consultation in 1996 for cases, and as 1 January 1997 for controls.

\section{Statistical analysis}

Demographic variables other than age and sex included body mass index (BMI), smoking, drinking, and deprivation. BMI was recorded for $83 \%$ of cases and $75 \%$ of controls, and the measurement closest to the baseline date was used. A BMI >25 was classified as overweight and $>30$ as obese. Smoking and drinking status is also incomplete and measured at different time points; people are crudely rated as smokers/non smokers and drinkers/non drinkers. Those with no recorded BMI, smoking or drinking status were classified as unknown for those variables to ensure they were not lost to the analysis. Each practice was allocated an Index of Multiple Deprivation score based on its geographical location. This score is a weighted index of components covering income; employment; health; education, skills and training; housing; and access to services. ${ }^{12}$ Individuals in this study were grouped according to the deprivation tertile category of their general practice.

The outcome period for measuring mortality was defined as a maximum of 10 years following the date of baseline consultation in 1996 for cases, and from 1 January 1997 for controls. Diagnoses of cancers were identified separately for the 2 years prior to the baseline consultation (1 January 1997 for controls) and for the 10 years following baseline consultation. Cancer was defined as a consultation for malignant or pre-malignant neoplasms under Chapter B of the Read Code hierarchy (Neoplasms); benign neoplasms, which are also coded in this chapter, were not included. 
In order to explore possible explanations of painrelated mortality in addition to cancer, pre-existing non-musculoskeletal comorbidity was also measured at baseline, as well as extracted records of osteoporosis and fracture diagnosed in the first year of follow-up. Non-musculoskeletal comorbidity was based on the number of diagnostic chapters (other than musculoskeletal) (Read Code Chapters A-Z) about which cases and controls had consulted in the 2 years prior to baseline; persons were categorised into low (0-2 Chapters), medium (3-5 Chapters) and high comorbidity ( $\geq 6$ Chapters). Osteoporosis was defined as having the Read Code N33 (Other bone/cartilage disorders [osteoporosis]). Fractures were identified from relevant injury (Chapter $\mathrm{S}$ ) and musculoskeletal diagnostic codes, and surgical procedure codes.

Crude mortality rates and cancer incidence rates during the entire follow-up period, and separately for the first year of follow-up, were calculated for all cases and controls, and for each case group. Persons with a pre-baseline diagnosis of cancer were excluded from the incidence-rate calculations for cancer. Date of death or cancer was defined as first recorded date of such in the GPRD records. Persons leaving the study because of departure from practice or departure of practice from GPRD added their proportion of follow-up at time of leaving the

Table 1. Sub-groupings of cases based on region of first musculoskeletal consultation in 1996 (baseline).

\begin{tabular}{lc}
\hline Back & $n(\%)$ \\
\hline Knee & $9259(19)$ \\
\hline Shoulder & $4170(9)$ \\
\hline Neck & $3639(8)$ \\
\hline Hand / wrist & $3331(7)$ \\
\hline Lower limb & $3293(7)$ \\
\hline Foot & $3138(7)$ \\
\hline Arm & $3119(6)$ \\
\hline Hip & $2844(6)$ \\
\hline Ankle & $2084(4)$ \\
\hline Chest & $1541(3)$ \\
\hline Pelvis & $1138(2)$ \\
\hline Head & $624(1)$ \\
\hline Limb & $340(<1)$ \\
\hline Buttock & $167(<1)$ \\
\hline Abdomen / trunk & $97(<1)$ \\
\hline More than 1 region ${ }^{b}$ & $38(<1)$ \\
\hline Unspecified & $684(1)$ \\
\hline Total cases & $8700(18)$ \\
\hline atother & 48206 \\
\hline
\end{tabular}

${ }^{\mathrm{a} N o t}$ otherwise specified. ${ }^{\mathrm{b}}$ Multiple Codes for different regions. study to the denominator. Mortality and cancer incidence rates over the first year are expressed per 10000 person-years at risk. For the full (10-year) follow-up analysis, they are expressed per 10000 person-decades at risk. Standardised mortality ratios (SMRs), cancer incidence ratios, and pre-baseline cancer prevalence ratios, indirectly standardised by age and sex, were calculated with 95\% confidence intervals (Cls) (based on the Poisson distribution) using the control group as the index population.

The exploration of causes of mortality was developed by modelling the mortality rate during the first year of follow-up in case groups compared with controls. First the extent of clustering within practices was assessed using a two-level (persons within practice) multilevel logistic regression with mortality as the outcome and no independent variables. The amount of variation in mortality rates that was between practices was low $(1.1 \%$ of all variation). When the independent variables were then included in the model the coefficients and standard errors were virtually identical to those from a single level logistic regression. Therefore, in order to take into account time to event, a single level Cox proportional hazards regression was used for the main analysis, with censuring at the earliest of last collected data point, point of death, departure from practice, or the point at which the practice no longer contributed to GPRD. The first model was adjusted for age, sex, BMI status, smoking status, drinking status, and deprivation.

Associations with mortality were then further adjusted for separately: non-musculoskeletal comorbidity in the 2 years prior to baseline, diagnosis of cancer in the 2 years prior to baseline or first year of follow-up, and osteoporosis and fracture in the first year of follow-up. The final model included all these measures. A further analysis repeated the process but excluded those with a pre-baseline diagnosis of cancer. The proportionality assumption was assessed graphically and using Schoenfeld residuals ${ }^{13}$ and deemed reasonable for this data. Analysis was performed using SPSS 15 for Windows, Stata 10 for Windows and CIA. ${ }^{14}$

\section{RESULTS}

\section{Subjects}

There were 48206 cases with a new consulting episode of musculoskeletal problems identified within the GPRD from 179 general practices, and 40254 controls; 38822 (81\%) consulted for a single, specified region (Table 1). The back was the most predominant region (19\% of cases), followed by the knee (9\%). Fifty-six per cent of cases and controls had more than 9 years of follow-up. The median (interquartile range [IQR]) length of follow-up was 
Table 2. Demographic characteristics of groups at baseline. ${ }^{a}$

\begin{tabular}{|c|c|c|c|c|c|c|c|c|c|}
\hline & Back & Knee & Shoulder & Neck & Hand/wrist & Foot & Hip & All Cases & Controls \\
\hline$N$ & 9259 & 4170 & 3639 & 3331 & 3293 & 3119 & 2084 & 48206 & 40254 \\
\hline Female & $5036(54)$ & $2198(53)$ & $1874(51)$ & $1803(54)$ & $1748(53)$ & $1727(55)$ & $1380(66)$ & $26911(56)$ & $22109(55)$ \\
\hline Mean age at baseline (SD), years & $65.0(10.9)$ & $66.5(10.8)$ & $65.0(10.8)$ & $64.1(10.6)$ & $65.0(10.9)$ & $65.0(10.6)$ & $70.6(11.4)$ & $65.9(11.1)$ & $66.5(10.8)$ \\
\hline \multicolumn{10}{|l|}{ BMI } \\
\hline Underweight $(<18.5)$ & $176(2)$ & $38(1)$ & $45(1)$ & $47(2)$ & $59(2)$ & $39(1)$ & $42(3)$ & 779 (2) & $659(2)$ \\
\hline Normal (18.5-25) & $3168(41)$ & $1156(33)$ & $1245(40)$ & $1256(44)$ & $1222(44)$ & $984(37)$ & $619(39)$ & $16163(40)$ & $13078(43)$ \\
\hline Overweight (25-30) & $3067(40)$ & $1523(44)$ & $1248(40)$ & $1181(41)$ & 1075 (39) & $1087(41)$ & $630(40)$ & $16042(40)$ & 11711 (39) \\
\hline Obese $(>30)$ & $1280(17)$ & $760(22)$ & $545(18)$ & $403(14)$ & 408 (15) & $543(20)$ & 289 (18) & $7053(18)$ & $4710(16)$ \\
\hline \multicolumn{10}{|l|}{ Deprivation status } \\
\hline Most deprived & $2626(37)$ & $1300(39)$ & $1085(39)$ & 972 (37) & $930(36)$ & $930(38)$ & $574(37)$ & $14004(37)$ & $11760(38)$ \\
\hline \multicolumn{10}{|c|}{ Number of Read Code Chapters recorded in 2 years pre-baseline } \\
\hline $0-2$ & $5305(57)$ & $2592(62)$ & $2180(60)$ & $1795(54)$ & $2010(61)$ & $1765(57)$ & $1159(56)$ & $27484(57)$ & $29850(74)$ \\
\hline $3-5$ & 3337 (36) & $1368(33)$ & $1222(34)$ & 1309 (39) & 1107 (34) & $1158(37)$ & 789 (38) & $17516(36)$ & $9316(23)$ \\
\hline$\geq 6$ & $617(7)$ & $210(5)$ & $237(7)$ & $227(7)$ & $176(5)$ & $196(6)$ & $136(7)$ & $3206(7)$ & $1088(3)$ \\
\hline
\end{tabular}

${ }^{\text {a }} n(\%)$ unless otherwise stated.

9.7 years (4.7-10.0 years) for cases and 9.4 years (4.5-9.7 years) for controls.

\section{Demographic characteristics}

The case groups were generally similar to each other, and to the controls, in terms of age, sex, and deprivation (Table 2). People in the hip group were older (mean 70.6 years compared to 65.9 years for all cases) and more likely to be female (66\% versus $56 \%)$. The knee group had the largest proportion of people who were overweight or obese.

\section{Mortality}

First-year mortality was 373 per 10000 person-years at risk in the case group and 244 per 10000 personyears at risk in the control group (Table 3). Figures were highest for the hip (746 per 10000 personyears), back (451 per 10000 person-years), and shoulder (310 per 10000 person-years) groups. Standardised mortality ratios (SMRs) exceeded 2.00 for the hip and back groups, and the SMR for the shoulder group was 1.42 . The mortality rate in cases over the 10-year follow-up period was closer to controls than in the first year.

\section{Recorded cancers}

In the 2 years prior to baseline, there was a higher prevalence of cancer diagnosis in cases (322 per 10000 persons) than controls (249 per 10000 persons) (Table 4). The highest proportions of prior cancer recording were for the hip, back, and shoulder groups with age-sex standardised cancer prevalence ratios of 1.3-1.5 compared to control group. The highest incidences of cancers in the 1 year following baseline were for the back (standardised incidence ratio $[S I R]=1.79)$, hip $(S I R=1.34)$, and neck $(S I R=$ 1.28) groups. These ratios were lower at 10-year follow-up but still indicated excess risk of cancer diagnosis (SIRs of 1.15 to 1.25 ) for these groups.

Modelling of mortality risk in the first year following musculoskeletal consulting episode

Risk of mortality in the first year was significantly higher for hip, back, and shoulder groups compared to controls after adjustment for age, sex, BMI, smoking, drinking, and deprivation (Table 5). The adjusted hazard ratios (HRs) show that some of the extra risk of mortality in the hip, back, and shoulder groups was explained by cancers and by nonmusculoskeletal comorbidity at baseline. For the hip group, adjusting for recorded fracture reduced the

Table 3. Comparison of mortality rates during follow-up by group.

\begin{tabular}{|c|c|c|c|c|c|}
\hline \multirow[b]{2}{*}{ Group } & \multirow[b]{2}{*}{$\begin{array}{c}\text { Number of } \\
\text { persons }\end{array}$} & \multicolumn{2}{|c|}{$\begin{array}{l}\text { Mortality in first } \\
\text { year of follow-up }\end{array}$} & \multicolumn{2}{|c|}{$\begin{array}{c}\text { Mortality in } \\
\text { 10-year follow-up }\end{array}$} \\
\hline & & $\begin{array}{c}\text { Rate per } 10000 \\
\text { person-years }\end{array}$ & $\begin{array}{c}\text { SMR } \\
(95 \% \mathrm{Cl})\end{array}$ & $\begin{array}{l}\text { Rate per } 10000 \\
\text { person-decades }\end{array}$ & $\begin{array}{c}\text { SMR } \\
(95 \% \mathrm{Cl})\end{array}$ \\
\hline Controls & 40254 & 244 & 1.00 & 2940 & 1.00 \\
\hline Back & 9259 & 451 & $\begin{array}{c}2.07 \\
\text { (1.87 to } 2.28)\end{array}$ & 3006 & $\begin{array}{c}1.17 \\
\text { (1.12 to } 1.22 \\
\end{array}$ \\
\hline Knee & 4170 & 220 & $\begin{array}{c}0.90 \\
(0.72 \text { to } 1.10)\end{array}$ & 2740 & $\begin{array}{c}0.92 \\
(0.86 \text { to } 0.99\end{array}$ \\
\hline Shoulder & 3639 & 310 & $\begin{array}{c}1.42 \\
(1.17 \text { to } 1.71) \\
\end{array}$ & 2604 & $\begin{array}{c}0.97 \\
(0.90 \text { to } 1.05 \\
\end{array}$ \\
\hline Neck & 3331 & 230 & $\begin{array}{c}1.13 \\
\text { (0.89 to } 1.41)\end{array}$ & 2467 & $\begin{array}{c}0.98 \\
\text { (0.91 to } 1.06\end{array}$ \\
\hline Hand/wris & ist 3293 & 185 & $\begin{array}{c}0.83 \\
\text { (0.64 to } 1.07)\end{array}$ & 2541 & $\begin{array}{c}0.94 \\
\text { (0.87 to } 1.02\end{array}$ \\
\hline Foot & 3119 & 220 & $\begin{array}{c}1.02 \\
(0.79 \text { to } 1.30)\end{array}$ & 2635 & $\begin{array}{c}1.00 \\
\text { (0.92 to } 1.08\end{array}$ \\
\hline Hip & 2084 & 746 & $\begin{array}{c}2.36 \\
\text { (1.99 to } 2.77)\end{array}$ & 4699 & $\begin{array}{c}1.32 \\
(1.22 \text { to } 1.43\end{array}$ \\
\hline All cases & 48206 & 373 & $\begin{array}{c}1.59 \\
\text { (1.52 to } 1.66)\end{array}$ & 3079 & $\begin{array}{c}1.11 \\
\text { (1.09 to } 1.13\end{array}$ \\
\hline
\end{tabular}

SMR = Age- and sex-standardised mortality ratio . 


\begin{tabular}{|c|c|c|c|c|c|c|}
\hline \multirow[b]{2}{*}{ Group } & \multicolumn{2}{|c|}{$\begin{array}{c}\text { Prevalence in } \\
2 \text { years pre-baseline }\end{array}$} & \multicolumn{2}{|c|}{$\begin{array}{l}\text { Incidence in } \\
\text { first year of follow-up }\end{array}$} & \multicolumn{2}{|c|}{$\begin{array}{c}\text { Incidence in } \\
\text { 10-year follow-up }\end{array}$} \\
\hline & $\begin{array}{l}\text { Rate per } \\
10000 \\
\text { persons }\end{array}$ & $\begin{array}{c}\text { SPR } \\
(95 \% \mathrm{Cl})\end{array}$ & $\begin{array}{c}\text { Rate per } \\
10000 \\
\text { person-years }\end{array}$ & $\begin{array}{c}\mathrm{SIR} \\
(95 \% \mathrm{Cl})\end{array}$ & $\begin{array}{c}\text { Rate per } \\
10000 \\
\text { person-decades }\end{array}$ & $\begin{array}{c}\text { SIR } \\
\text { es }(95 \% \mathrm{Cl})\end{array}$ \\
\hline Controls & 249 & 1.00 & 167 & 1.00 & 1817 & 1.00 \\
\hline Back & 356 & $\begin{array}{c}1.51 \\
\text { (1.35 to } 1.69) \\
\end{array}$ & 280 & $\begin{array}{c}1.79 \\
(1.57 \text { to } 2.03)\end{array}$ & 2135 & $\begin{array}{c}1.25 \\
\text { (1.19 to } 1.32) \\
\end{array}$ \\
\hline Knee & 278 & $\begin{array}{c}1.12 \\
\text { (0.93 to } 1.35)\end{array}$ & 172 & $\begin{array}{c}1.03 \\
(0.80 \text { to } 1.31)\end{array}$ & 2016 & $\begin{array}{c}1.11 \\
\text { (1.02 to } 1.20)\end{array}$ \\
\hline Shoulder & 313 & $\begin{array}{c}1.34 \\
\text { (1.10 to } 1.61)\end{array}$ & 195 & $\begin{array}{c}1.24 \\
\text { (0.96 to } 1.57)\end{array}$ & 1977 & $\begin{array}{c}1.13 \\
\text { (1.04 to } 1.24)\end{array}$ \\
\hline Neck & 279 & $\begin{array}{c}1.22 \\
\text { (0.98 to } 1.49) \\
\end{array}$ & 197 & $\begin{array}{c}1.28 \\
(0.98 \text { to } 1.64)\end{array}$ & 2032 & $\begin{array}{c}1.20 \\
\text { (1.09 to } 1.31) \\
\end{array}$ \\
\hline Hand/wrist & t 255 & $\begin{array}{c}1.09 \\
(0.87 \text { to } 1.35) \\
\end{array}$ & 156 & $\begin{array}{c}0.99 \\
\text { (0.73 to } 1.31)\end{array}$ & 1793 & $\begin{array}{c}1.03 \\
\text { (0.93 to } 1.13) \\
\end{array}$ \\
\hline Foot & 279 & $\begin{array}{c}1.17 \\
\text { (0.94 to } 1.45)\end{array}$ & 170 & $\begin{array}{c}1.05 \\
\text { (0.78 to } 1.39)\end{array}$ & 1911 & $\begin{array}{c}1.08 \\
\text { (0.98 to } 1.19)\end{array}$ \\
\hline Hip & 413 & $\begin{array}{c}1.45 \\
\text { (1.16 to } 1.79)\end{array}$ & 252 & $\begin{array}{c}1.34 \\
\text { (0.99 to } 1.78)\end{array}$ & 2249 & $\begin{array}{c}1.15 \\
(1.02 \text { to } 1.29)\end{array}$ \\
\hline All cases & 322 & $\begin{array}{c}1.32 \\
(1.26 \text { to } 1.39)\end{array}$ & 222 & $\begin{array}{c}1.36 \\
\text { (1.28 to } 1.45)\end{array}$ & 2045 & $\begin{array}{c}1.16 \\
\text { (1.13 to } 1.19)\end{array}$ \\
\hline
\end{tabular}

$S I R=$ Age- and sex-standardised incidence ratio. SPR = Age- and sex-standardised prevalence ratio. ${ }^{2} / \mathrm{n}$ those without a cancer consultation in 2 years pre-baseline.

hazard ratio, but adjusting for recorded osteoporosis had no effect. After adjustment for all measures, an increased risk of mortality persisted for the hip (HR $1.72 ; 95 \% \mathrm{Cl}=1.43$ to 2.07 ), back (HR $1.68 ; 95 \% \mathrm{Cl}$ $=1.49$ to 1.90$)$, and shoulder $(\mathrm{HR} 1.28 ; 95 \% \mathrm{Cl}=$ 1.05 to 1.56 ) groups. Restricting the analysis to those without a pre-baseline diagnosis of cancer slightly reduced the hazard ratios adjusted for all comorbidity (hip: $1.64 ; 95 \% \mathrm{Cl}=1.34$ to 2.01 ; back: $1.56 ; 95 \% \mathrm{Cl}=1.36$ to 1.78 ; shoulder: $1.17 ; 95 \% \mathrm{Cl}$ $=0.94$ to 1.47 ).

\section{DISCUSSION}

\section{Summary of main findings}

This study has examined regional musculoskeletal problems in persons aged $\geq 50$ years with no recent history of consulting about musculoskeletal problems. Mortality during the first year after presentation was higher in individuals whose new episode was located in the back, hip, or shoulder compared to controls, and this could not be fully explained by cancer or other comorbidity present at the time of the index consultation. These differences diminished substantially in size after 10 years.

The incidence of cancer diagnosis was higher among cases than controls during the first year following the musculoskeletal consultation, particularly for those consulting with back problems. The difference between cases and controls was still detectable, although reduced in size, over 10 years of follow-up.

\section{Strengths and limitations of the study}

It has been demonstrated that GPRD guidelines on recording of repeat consultations leads to underestimate of consultation prevalence for chronic musculoskeletal problems. ${ }^{15}$ However, it is a requirement of the GPRD that morbidity codes are entered at first diagnosis and hence incident cases should be comprehensively recorded. It is possible that symptoms of cancer may be recorded elsewhere than under the Neoplasms Chapter prior to diagnosis of cancer but the authors of this study were interested in determining malignant and premalignant neoplasms with a definitive diagnosis. It is unlikely that any cancer diagnoses recorded elsewhere would affect the associations found. Benign neoplasms were excluded. Future work will investigate whether back and hip pain is linked to specific types of cancer.

Table 5. Effect of comorbidity on risk of mortality during first year of follow-up.

\begin{tabular}{|c|c|c|c|c|c|c|}
\hline Group & $\begin{array}{l}\text { No comorbidity } \\
\text { adjustment } \\
\text { HR }(95 \% \text { Cl) }\end{array}$ & $\begin{array}{c}\text { Adjusted for } \\
\text { cancer diagnosis } \\
\text { HR }(95 \% \mathrm{Cl})\end{array}$ & $\begin{array}{l}\text { Adjusted for } \\
\text { recorded osteoporosis } \\
\text { HR }(95 \% \mathrm{Cl})\end{array}$ & $\begin{array}{l}\text { Adjusted for } \\
\text { recorded fracture }{ }^{\mathrm{a}, \mathrm{d}} \\
\text { HR }(95 \% \mathrm{Cl})\end{array}$ & $\begin{array}{c}\text { Adjusted for } \\
\text { general comorbiditya,e } \\
\text { HR }(95 \% \mathrm{Cl})\end{array}$ & $\begin{array}{c}\text { Adjusted for all } \\
\text { comorbidity measures }^{a-e} \\
\text { HR }(95 \% \mathrm{Cl})\end{array}$ \\
\hline Controls & 1.00 & 1.00 & 1.00 & 1.00 & 1.00 & 1.00 \\
\hline Back & 2.17 (1.93 to 2.43 ) & 1.92 (1.71 to 2.16 ) & 2.14 (1.90 to 2.41$)$ & 2.15 (1.91 to 2.42 ) & 1.77 (1.57 to 1.99$)$ & 1.68 (1.49 to 1.90$)$ \\
\hline Knee & 1.00 (0.80 to 1.24$)$ & 0.94 (0.76 to 1.17$)$ & 1.00 (0.80 to 1.24$)$ & 0.99 (0.79 to 1.22$)$ & 0.89 (0.71 to 1.10$)$ & 0.88 (0.70 to 1.09$)$ \\
\hline Shoulder & 1.49 (1.22 to 1.81$)$ & 1.45 (1.19 to 1.76$)$ & 1.49 (1.22 to 1.81$)$ & 1.46 (1.19 to 1.77$)$ & 1.24 (1.02 to 1.51$)$ & $1.28(1.05$ to 1.56$)$ \\
\hline Neck & 1.24 (0.98 to 1.57$)$ & 1.13 (0.90 to 1.43$)$ & 1.24 (0.98 to 1.56$)$ & 1.23 (0.97 to 1.56$)$ & 0.99 (0.78 to 1.26$)$ & 1.01 (0.79 to 1.27$)$ \\
\hline Hand/wrist & 0.90 (0.70 to 1.17$)$ & 0.89 (0.69 to 1.15$)$ & 0.90 (0.69 to 1.17$)$ & 0.83 (0.64 to 1.09$)$ & 0.77 (0.59 to 1.00$)$ & 0.75 (0.57 to 0.97$)$ \\
\hline Foot & 1.11 (0.86 to 1.42$)$ & 1.07 (0.84 to 1.37$)$ & 1.11 (0.86 to 1.42$)$ & 1.09 (0.85 to 1.39$)$ & $0.90(0.70$ to 1.16$)$ & 0.93 (0.73 to 1.20$)$ \\
\hline Hip & 2.27 (1.90 to 2.70$)$ & 2.10 (1.76 to 2.50$)$ & 2.26 (1.90 to 2.70$)$ & 2.06 (1.71 to 2.48 ) & 1.94 (1.62 to 2.31$)$ & 1.72 (1.43 to 2.07$)$ \\
\hline
\end{tabular}

$H R=$ hazard ratio. ${ }^{a}$ Adjusted for age, sex, BMI, drinking, smoking, deprivation status. ${ }^{b}$ diagnosis of cancer in 2 years prior to baseline or 1 year after baseline. ${ }^{\mathrm{c}}$ Recorded osteoporosis in 1 year after baseline. ${ }^{\mathrm{d}}$ Recorded fracture at baseline or in 1 year after baseline. ${ }^{\mathrm{e}}$ Based on the number of diagnostic chapters for which subjects had consulted in the 2 years prior to baseline. Categorised into low (0-2 chapters), medium (3-5 chapters), and high comorbidity ( $\geq 6$ chapters). 
Two years free of consultation for musculoskeletal problems was arbitrarily selected as the definition of an incident case. It would be expected that ongoing consultations for the same problem would be recorded at least once during a 2-year period, if only to signify a change in treatment. The study participants are likely to represent older individuals with incident episodes of musculoskeletal problems, but may include some with long-term episodes that have worsened, or new episodes of longstanding problems.

The cause of death is not routinely recorded as part of the GPRD data collection and therefore it was not possible to ascertain the actual cause of death. Recording of death is quality assessed in the GPRD, and so should be of high validity. ${ }^{6,16}$ Based on the age and sex national mortality figures for England and Wales for 1998, 250 deaths per 10000 population were expected in the control group in the first year. The actual figure of 244 per 10000 suggests a comparable mortality rate in the control group to the UK general population.

This study has investigated regional problems rather than specific diagnoses. This matches community surveys of self-reported problems and is more relevant to the patient who will present initially with pain in a specific region, and who may not obtain a clear-cut diagnosis at the initial visit.

There was some loss to follow-up in terms of patients leaving the practice or their practice leaving the GPRD. There is no reason to believe these patients were substantially different to those with longer follow-up. Any differences should not affect the internal cohort comparisons which form the major analyses. The case and control groups had similar lengths of follow-up. The nature of the matching meant some controls were allocated to more than one case. Again this should not affect the conclusions, particularly relating to the differences between case groups.

The method of estimation of comorbidity was crude and does not reflect comorbidity occurring within the same Read Code Chapter. However, morbidity prevalence across Chapters will reflect the wide range of co-existing morbidities with which patients present in primary care.

\section{Comparison with existing literature}

This study relates to patients who choose to consult their GP. The relative ranking of incidence of consultations for regional musculoskeletal syndromes in primary care is similar to that based on prevalence of pain as reported in population surveys. ${ }^{17,18}$ A Dutch study in general practice showed a reasonably similar ordering of incidence of hip, knee, leg, foot and ankle consultations. ${ }^{19}$
Individuals with inflammatory musculoskeletal disorders such as rheumatoid arthritis have been shown in GPRD data to have higher mortality rates than those with osteoarthritis or no arthritis, ${ }^{20}$ but such conditions would form only a small minority of the new-episode consultations studied here. Diagnosed osteoporosis did not explain the higher mortality, although there is evidence from elsewhere that osteoporosis confers a mortality risk. ${ }^{21,22}$ However, osteoporosis may not be symptomatic or may not necessarily be diagnosed when present, and so misclassification is a possible explanation of this finding.

There is a currently unexplained risk of higher mortality in older persons presenting with back and hip problems in particular. This may link with the observation of increased mortality in adults reporting chronic widespread pain in the general population, ${ }^{2-4}$ although that finding has not been consistently replicated in different populations. ${ }^{23}$ Higher mortality in the present study groups might be restricted to persons with concurrent widespread pain in other locations. However, since the standard definition of widespread pain includes back or neck pain, it is equally plausible that back pain-associated mortality explains the earlier observations. The widespread pain studies tended to rule out psychological distress as an explanation of increased mortality; in this study underlying comorbidity did not explain it. General population studies have also identified a link of mortality with regional pain ${ }^{3,4}$ although a Swedish study found elevated risk of mortality in those reporting pain in arms or legs but, in contrast to the current study, not for the back or hips. ${ }^{24} \mathrm{~A}$ study of chronic pain in women did not find an association with mortality or cancer. ${ }^{5}$ Entry criteria for this study's patients was based on a single consultation, and it is impossible to know what proportion were presenting with acute pain and what proportion had chronic pain for which they had not previously consulted. So this study does not investigate links with chronic pain specifically.

Previous studies did not assess short-term followup, which is where the current study identified the greatest risk. There is a small but consistent elevated mortality associated with the presentation of certain musculoskeletal problems in general practice, particularly in the first year after a new consulting episode, which remains unexplained.

\section{Implications for future research and clinical practice}

An important question is the likelihood of serious underlying problems in persons presenting with new musculoskeletal episodes. This study is reassuring. As an example, the figures would indicate that, in 
1000 consulters in this age group with a new episode of a back problem, there will be approximately 22 extra deaths than expected in the 12 months following the back consultation. Of these 22 cases, about seven would already have a cancer diagnosis. The figures also suggest that, in such a group of 1000 consulters, there will be approximately 24 extra cases of cancer linked to the back consultation; about 12 of these would already have been diagnosed prior to the back pain presentation. What is uncertain is how many of the 12 additional cases of cancer might have red flag symptoms and signs that could distinguish them from the other new back pain sufferers at the time of consultation. Clinical studies on such low-frequency events are difficult to conduct. However, the association between clinical features and red flag diagnoses is not strong. ${ }^{1,25}$ Clinical alertness to the possibility seems the practical conclusion, but further observational studies to reassure healthcare professionals that the current triage process in primary care does not lead to delays in cancer diagnosis would be helpful.

\section{Linked commentary}

This article has an associated commentary: Smith BH. This pain is killing me. Br J Gen Pract 2010; DOI: 10.3399/bjgp10X483805.

\section{Funding body}

Use of the GPRD was partly funded by a Medical Research Council equipment grant. The authors are independent of the funders. The funders played no role in the study.

\section{Ethical approval}

The study was approved by the GPRD Independent Scientific Advisory Committee (ISAC) (project 06-069).

\section{Conflicts of interest}

The authors have stated that there are none.

\section{Discuss this article}

Contribute and read comments about this article on the Discussion Forum: http://www.rcgp.org.uk/bjgp-discuss

\section{REFERENCES}

1. Henschke N, Maher CG, Refshauge KM. Screening for malignancy in low back pain patients: a systematic review. Eur Spine J 2007; 16(10): 1673-1679.

2. McBeth J, Silman AJ, Macfarlane GJ. Association of widespread body pain with an increased risk of cancer and reduced cancer survival: a prospective, population-based study. Arthritis Rheum 2003; 48(6): 1686-1692.

3. McBeth J, Symmons DP, Silman AJ, et al. Musculoskeletal pain is associated with a long-term increased risk of cancer and cardiovascular-related mortality. Rheumatology 2009; 48(1): 74-77.

4. Macfarlane GJ, McBeth J, Silman AJ. Widespread body pain and mortality: prospective population based study. BMJ 2001; 323(7314): 662-665.
5. Smith BH, Elliott AM, Hannaford PC. Pain and subsequent mortality and cancer among women in the Royal College of General Practitioners Oral Contraception Study. Br J Gen Pract 2003; 53(486): $45-46$.

6. Lawson DH, Sherman V, Hollowell J. The General Practice Research Database. Scientific and Ethical Advisory Group. QJM 1998; 91(6): 445-452.

7. Nazareth I, King M, Haines A, et al. Accuracy of diagnosis of psychosis on general practice computer system. BMJ 1993; 307: 32-34.

8. Lawrenson R, Todd JC, Leydon GM, et al. Validation of the diagnosi of venous thromboembolism in general practice database studies. $\mathrm{Br}$ J Clin Pharmacol 2000; 49: 591-596.

9. Lewis JD, Brensinger C, Bilker WB, Strom BL. Validity and completeness of the General Practice Research Database for studies of inflammatory bowel disease. Pharmacoepidemiol Drug Saf 2002; 11: $211-218$

10. Margolis DJ, Bilker W, Knauss J, et al. The incidence and prevalence of pressure ulcers among elderly patients in general medical practice. Ann Epidemiol 2002; 12: 321-325.

11. NHS Information Authority. The Clinical Terms Version 3 (The Read Codes). Birmingham: NHS Information Authority, 2000.

12. Department of the Environment, Transport and the Regions. Indices of deprivation 2000. London: Department of the Environment, Transport and the Regions, 2000 .

13. Grambsch PM, Therneau TM. Proportional hazards tests and diagnostics based on weighted residuals. Biometrika 1994; 81: 515-526.

14. Altman DG, Machin D, Bryant TN, Gardner MJ. Statistics with confidence. 2nd edn. London: BMJ Books, 2000.

15. Jordan K, Clarke AM, Symmons DP, et al. Measuring disease prevalence: a comparison of musculoskeletal disease using four general practice consultation databases. Br J Gen Pract 2007; 57: $7-14$

16. Meier CR, Jick H. Drug use and pulmonary death rates in increasingly symptomatic asthma patients in the UK. Thorax 1997, 52(7): 612-617.

17. Picavet HS, Schouten JS. Musculoskeletal pain in the Netherlands: prevalences, consequences and risk groups, the $\mathrm{DMC}(3)$-study. Pain 2003; 102: 167-178

18. Thomas E, Peat G, Harris L, et al. The prevalence of pain and pain interference in a general population of older adults: cross-sectional findings from the North Staffordshire Osteoarthritis Project (NorStOP). Pain 2004;110:361-368.

19. Van der Waal JM, Bot SD, Terwee CB, et al. The incidences of and consultation rate for lower extremity complaints in general practice. Ann Rheum Dis 2006;65:809-815

20. Watson DJ, Rhodes T, Guess HA. All-cause mortality and vascular events among patients with rheumatoid arthritis, osteoarthritis, or no arthritis in the UK General Practice Research Database. J Rheumatol 2003; 30(6): 1196-1202.

21. Riggs BL, Melton LJ 3rd. The worldwide problem of osteoporosis: insights afforded by epidemiology. Bone 1995; 17(5 Suppl): 505S$511 \mathrm{~S}$

22. Lau EMC. Epidemiology of osteoporosis. Best Pract Res Clin Rheumatol 2001; 15(3): 335-344.

23. Macfarlane GJ, Jones GT, Knekt P, et al. Is the report of widespread body pain associated with long-term increased mortality? Data from the Mini-Finland Health Survey. Rheumatology (Oxford) 2007; 46(5): 805-807.

24. Kåreholt I, Brattberg G. Pain and mortality risk among elderly persons in Sweden. Pain 1998; 77(3): 271-278.

25. Henschke N, Maher CG, Refshauge KM. A systematic review identifies five 'red flags' to screen for vertebral fracture in patients with low back pain. J Clin Epidemiol 2008; 61(2): 110-118. 


\section{COMMENTARY}

\section{This pain is killing me}

The article by Jordan and Croft reports the latest in a series of studies that have examined possible links between the presence of musculoskeletal disease and subsequent mortality and/or cancer. ${ }^{1}$ Other studies have reported somewhat conflicting results, with varying strengths and degrees of specificity of associations found. Significant relationships between mortality and pain, dependent upon the location, type or extent of pain, have been reported, ${ }^{2-4}$ with most of the excess mortality associated with widespread pain attributable to cancer. ${ }^{5}$ Other links have been suggested between widespread pain and increased cancer and cardiovascular mortality, ${ }^{6,7}$ and between severe chronic pain and overall mortality and cardiovascular and respiratory disease mortality. ${ }^{8}$ In contrast, another recent study found no significant association between pain and mortality. ${ }^{9}$ It is likely that differences in the findings between these studies are attributable to the research being conducted on different populations, using different case definitions and methods of recording outcomes, and adjusting (or not adjusting) for different potential confounders. Certainly, an important recommendation following the early research was that further corroboration is required, ${ }^{10}$ and this remains the case.

To that end, Jordan and Croft have used a good quality database, and theirs is easily the largest study to examine the possible associations to date. They found clear and substantial links between new presentations of musculoskeletal conditions, in those aged $\geq 50$ years, and subsequent death (especially within 1 year) and also subsequent cancer. The links were strongest after presentation with a back or hip condition, and detailed statistical analysis shows that they could not be substantially explained by a wide range of sociodemographic or other pre-existing clinical factors.

There are four possible (not mutually exclusive) conclusions from a reading of all this research: (1) pain and/or musculoskeletal disease causes death and/or cancer; (2) the same factors that cause pain and/or musculoskeletal disease also cause death and/or cancer; (3) other factors and pain/musculoskeletal disease combine together to cause death and/or cancer; or (4) the findings arise through chance, and there is no genuine link. Jordan and Croft provide the clearest evidence yet of a genuine link, but cannot distinguish the other three potential explanations. In particular, they cannot establish causality.

So what does this mean for us as GPs? As the authors state, it should certainly heighten our awareness of the potential gravity of any presentation with chronic pain or a musculoskeletal disorder; the excess associated mortality and cancer risk, although modest, are nonetheless important. However, further work is clearly required before the findings can be applied at an individual level; we need to know ways of identifying which patients are most at risk of developing these serious outcomes. And, apart from increased vigilance, we need to test the implied hypothesis that adequate investigation and management would reduce this risk. Meanwhile, however, although the precise nature of the links are still to be elucidated, the emerging consensus that musculoskeletal disease and pain are in some way associated with subsequent cancer and death, coming on top of the well-known link with overall poor health and disability, means that we must now take the management of pain very seriously indeed. The best way of doing that is a different question entirely.

\section{Blair H Smith,}

Professor of Primary Care Medicine, Centre of Academic Primary Care, University of Aberdeen, Foresterhill Health Centre, Westburn Road, Aberdeen AB25 2AY. E-mail: blairsmith@abdn.ac.uk

\section{Provenance}

Commissioned; not peer reviewed

\section{REFERENCES}

1. Jordan KP, Croft P. Mortality and cancer in patients with new musculoskeletal episodes: a cohort study. Br J Gen Pract 2010; DOI: 10.3399/bjgp10X483526.

2. Kareholt I, Brattberg G. Pain and mortality risk among elderly persons in Sweden. Pain 1998; 77: 271-278.

3. Smith BH, Elliott AM, Hannaford PC. Pain and subsequent mortality and cancer among women in the Royal College of General Practitioners Oral Contraception Study. Br J Gen Pract 2003; 53: 45-46.

4. Andersson HI. The course of non-malignant chronic pain: a 12-year follow-up of a cohort from the general population. Eur J Pain 2004; 8: 47-53.

5. Macfarlane GJ, McBeth J, Silman AJ. Widespread body pain and mortality: prospective population based study. BMJ 2001; 323: 662-665.

6. McBeth J, Silman AJ, Macfarlane GJ. Association of widespread body pain with an increased risk of cancer and reduced cancer survival: a prospective, population-based study. Arthritis Rheum 2003; 48: 1686-1692.

7. McBeth J, Symmons DP, Silman AJ, et al. Musculoskeletal pain is associated with a long-term increased risk of cancer and cardiovascular-related mortality. Rheumatology 2009; 48: 74-77.

8. Torrance N, Elliott AM, Lee AJ, Smith BH. Severe chronic pain is associated with increased 10 year mortality. A cohort record linkage study. Eur J Pain 2009 [Epub ahead of print (doi:10.1016/j.ejpain.2009.07.006)]

9. Macfarlane GJ, Jones GT, Knekt P, et al. Is the report of widespread body pain associated with long-term increased mortality? Data from the Mini-Finland Health Survey Rheumatology 2007; 46: 805-807.

10. Crombie IK. Commentary: an interesting finding, but what does it mean? BMJ 2001; 323: 664-665.

DOI: 10.3399/bjgp10X483805 